\title{
Compare the Effects of Dexmedetomidine Infusion versus Normal Saline as Placebo on Haemodynamic Response in Elective Laparoscopic Surgery Under General Anaesthesia
}

\author{
V. Ravi Sankar ${ }^{\circledR 1}$, T. Jamuna ${ }^{\circledR 2}$, B. Raju ${ }^{\circledR 3}$ \\ ${ }^{1}$ Assistant Professor, Department of Anesthesia, S.V. Medical College, Tirupati, Chitoor, Andhra Pradesh, India, ${ }^{2}$ HOD and Professor, Department of Anesthesia, S.V. \\ Medical College, Tirupati, Chitoor, Andhra Pradesh, India, ${ }^{3}$ Post Graduate, Department of Anesthesia, S.V. Medical College, Tirupati, Chitoor, Andhra Pradesh, India.
}

\section{Abstract}

Background: Throughout the present medical age, laparoscopic surgery is the most effective diagnostic and therapeutic methods. But it is associated with potentially harmful neuroendocrine response. Subjects and Methods: In our study we used dexmedetomidine infusion in group $\mathrm{D}$ and normal saline at a rate of $0.4 \mathrm{mcg} / \mathrm{kg} / \mathrm{hr}$ as placebo in group $\mathrm{N}$ beginning from 10 minutes before induction before pneumoperitoneum release. Patients in both groups were alike in age, gender, BMI, grade of ASA and anaesthesia. Results: After 10 min infusion of dexmedetomidine and normal saline in group D and group $\mathrm{N}$ respectively, fall in HR, DBP and Mean arterial pressure was significantly increased in group D compared to group N. Difference found in both the groups was statistically significant. Group N showed significant increase in HR, SBP, DBP and MAP during laryngoscopy, intubation and at $2 \mathrm{~min}, 5 \mathrm{~min}$ and $10 \mathrm{~min}$ after creation of pneumoperitoneum. Difference found was statistically significant in both groups. Thus attenuation in HR, SBP, DBP and MAP was seen in group D as compared to group N during laryngoscopy, tracheal intubation and pneumoperitoneum which were statistically significant. Group N showed statically significant increase in HR, DBP and MAP during extubation compared to group D. Difference found in both the groups was statistically significant. Thus attenuation in HR, DBP and MAP was seen in group D as compared to group N during extubation which was statistically significant. Postoperative sedation score was more in group D compared to group $\mathrm{N}$ which was statistically significant. Post-extubation, rescue analgesia was required early in group $\mathrm{N}$ compared to group D. Adverse effect in form of bradycardia was seen in 2 patients in group D which did not require atropine administration. Conclusion: Dexmedetomidine infusion at a rate of $0.4 \mathrm{mcg} / \mathrm{kg} / \mathrm{hr}$ apparently started 10 minutes before the induction of anesthesia before release of pneumoperitoneum without any bolus dose. Useful adjuvant anesthesia to diminish the response of haemodynamic stress to intubation, Pneumoperitoneum, and extubation in laparoscopic surgical patients.

Keywords: Dexmedetomidine, Laparoscopy, Placebo

Corresponding Author: T. Jamuna, HOD and Professor, Department of Anesthesia, S.V. Medical College, Tirupati, Chitoor, Andhra Pradesh, India.

E-mail: drtjamuna@gmail.com

Received: 01 January 2020

Revised: 29 January 2020

Accepted: 04 February 2020

Published: 16 December 2020

\section{Introduction}

There has been a relentless quest for new surgical modalities, procedures and equipment since the beginning of medicine's surgical period. The twentieth century saw the dawn of a modern surgical method, which was broadly accepted by both the patients and surgical fraternity. Minimally invasive surgery nearly revolutionized surgical care across a wide range of diseases.

The importance of performing an internal examination of the many compartments of the human body has been recognized for several centuries. He realised that pnemoperitoneum was important for exposure and hence used room air for insufflation of the peritoneal cavity:

Throughout the present medical age, laparoscopic medical procedure is one of the best demonstrative and helpful methods. Laparoscopy advantages include shorter hospital stay, faster return to daily life, reduced discomfort and fewer incisions. ${ }^{[1]}$ New surgical methods, however, turn into additional anaesthetic problems that include improvements in anaesthetic techniques. Although it has certain benefits over traditional surgery, it comes at the expense of potentially adverse neuroendocrine reaction. 
Pneumoperitoneum is produced by carbon dioxide $(\mathrm{CO} 2)$ insufflation during laparoscopic surgical procedures. ${ }^{[2]}$ Both pneumoperitoneum and $\mathrm{CO} 2$ trigger side effects of the cardiovascular system. Some of these symptoms are $\mathrm{CO} 2$ associated, and others are due to higher intraabdominal pressure. Immediately after pneumoperitoneum, the activity of plasma norepinephrine, epinephrine, and plasma renin rises. The elevated level of catecholamine also stimulates the reninangiotensin - aldosterone pathway. Both of these progressions will in general lead to increases arterial pressure increase systemic and pneumonic vascular opposition, and reduced cardiac output, tachycardia, and once in a while arrhythmia. For high-risk patients particularly those with cardiopulmonary conditions these insults can be devastating. Hence, recognizing pathophysiology and preserving haemodynamic control in these patients is of utmost importance.

Therefore, modern anaesthesia procedures aim to minimize sympathetic discharge to have perioperative haemodynamic control. To order to accomplish this goal with varying effectiveness, multiple agents to the form of opioid analgesics, benzodiazepines, beta blockers, calcium channel blockers and vasodilators have been employed. Thanks to their anxiolytic, sedative, sympatholytic and analgesic-sparing effects, a considerable enthusiasm have been shown in recent years towards the use of $\alpha 2$ agonists in anaesthesia research.

Dexmedetomidine decreases sympathetic tone, blood pressure, pulse rate and causes sedation. This also reduces anaesthetic agents and analgesics requirements intraoperatively. ${ }^{[3]}$ In some study reports, dexmedetomidine infusion levels ranging from 0.1 to $10 \mathrm{mcg} / \mathrm{kg} / \mathrm{hr}$ were used. ${ }^{[4]}$ Higher infusion levels trials have further incidences of adverse effects such as hypotension and bradycardia. ${ }^{[5]}$ In our study, dexmedetomidine at an infusion rate of $0.4 \mathrm{mcg} / \mathrm{kg} / \mathrm{hr}$ should be used during elective laparoscopic surgery under general anaesthesia. This placebo treatment controlled, randomized forthcoming investigation is intended to assess the impacts of dexmedetomidine infusion on haemodynamic reaction, postoperative sedation and absense of pain necessities in patients of indian phenotype experiencing elective laparoscopic medical procedure under general anaesthesia.

\section{Subjects and Methods}

It is Prospective, randomized, double blind, placebocontrolled study conducted in the department of Anaesthesiology, Sri Venteshwara Ramnarayan Ruia (SVRRGGH) Hospital, Tirupathi. The study will be conducted in $60-100$ ASA grade 1 and 2 patients between age group above 18 to 65 years, posted for elective laparoscopic surgery. The patients will be uniformly separated into 2 categories using a sealed-envelope system either to receive normal saline infusion (group N) or dexmedetomidine infusion (group D). Each group will be having 30-50 patients. Both groups will be comparable with regards to number, age, BMI, gender distribution and ASA grading. Sample size 27 cases (minimum in each intervention group, i.e. total 54 cases with Group N (Normal Saline) to Group D (Dexmedetomidin)

\section{Inclusion Criteria:}

ASA physical grade 1 and 2, Patients with age between above 18 to 65 years of either gender, who are willing to give written and informed consent for study and posted for elective laparoscopic surgery under general anaesthesia.

\section{Exclusion Criteria:}

ASA physical grade 3 and 4 patients, Patients who are not willing to give consent to participate, on alpha-2 agonists, Pregnant and lactating women and morbidly obese patients.

The data has collected in a pretested proforma meeting the objectives of the study upon receiving authorisation from the ethical institutional committee. Each patient was given a patient information sheet and informed written consent from the patient was obtained. A pre-anesthetic evaluation done on theevening before surgery, and patients were kept nil per oral 6 hours beforesurgery. The patients randomly allocated either to receive normal saline infusion (group $\mathrm{N}$ ) or dexmedetomidine infusion (group D). Each group had 30 patients.

For two patient groups, two separate infusions were held available, based on the group allocated. The dexmedetomidine infusion, available at a $50 \mathrm{mcg}$ concentration in $0.5 \mathrm{ml}$ of the drug, was removed in a $50 \mathrm{ml}$ syringe and was diluted up to $50 \mathrm{ml}$ with normal saline resulting in a final $1 \mathrm{mcg} / \mathrm{ml}$ concentration. The syringe pump which was used to infuse the drugs. Depending on the patient 's weight, the targeted infusion rate of dexmedetomidine supplied by the pump is 0.4 $\mathrm{mcg} / \mathrm{kg} / \mathrm{hr}$. Vital parameters such as baseline pulse rate (PR), systolic blood pressure (SBP), diastolic blood pressure (DBP), mean arterial pressure (MAP), and oxygen saturation were monitored and noted after the patient was taken on the operating table. A wide bore intravenous cannula was inserted for the intravenous IV fluids, and another venous line for the infusion was taken. Infusion of dexmedetomidine began at a rate of $0.4 \mathrm{mcg} / \mathrm{kg} / \mathrm{hr}$. Premedication given to all patients in the form of midazolam injection $(0.05 \mathrm{mg} / \mathrm{kg})$, fentanyl injection $(2 \mathrm{mcg} / \mathrm{kg})$, and ondansetron injection $(0.1 \mathrm{mg} /$ $\mathrm{kg}$ ) IV before induction of anesthesia. $10 \mathrm{~min}$ after infusion with thiopenton injection begins at $5 \mathrm{mg} / \mathrm{kg} \mathrm{IV}$, anesthesia was induced.

Endotracheal intubation with a suitable sized cuff facilitated with injection vecuronium $0.1 \mathrm{mg} / \mathrm{kg}$ as a muscle relaxant. Anesthesia maintained with oxygen, nitrous oxide, sevoflurane Furthermore, vecuronium top up (25\% of the initial dose, if required). All patients mechanically ventilated using a circle system. Respiratory rate (RR) and tidal volume were adjusted according to body weight to keep the EtCO2 between 35 and 
$45 \mathrm{~mm} \mathrm{Hg}$. Intra-abdominal pressure was maintained between 12 and $14 \mathrm{mmHg}$ throughout the laparoscopic procedure. Dexmedetomidine infusion stopped at the time of the release of pneumoperitoneum. Hemodynamic parameters HR, SBP, DBP, and MAP studied in both the study groups at a specific time. That is at baseline, $10 \mathrm{~min}$ after starting the infusion, during laryngoscopy and tracheal intubation, 2 min after intubation, just before the creation of pneumoperitoneum, $2 \mathrm{~min}, 5$ $\mathrm{min}$, and $10 \mathrm{~min}$ after the creation of pneumoperitoneum, just before and $2 \mathrm{~min}$ after release of pneumoperitoneum, during extubation and 2 min after extubation. Extubated after reversal was carried out with injection neostigmine $0.05 \mathrm{mg} / \mathrm{kg}$ and injection glycopyrrolate $0.01 \mathrm{mg} / \mathrm{kg}$ IV.

Postoperative sedation measured at $5 \mathrm{~min}, 15 \mathrm{~min}, 30 \mathrm{~min}$, and $60 \mathrm{~min}$ after extubation, using the Ramsay sedation score (RSS). Duration at which the analgesic prescribed indicated (duration from completion of the injection of a drug to the post-operative duration when pain recorded by the patient was roughly 4 on the visual analog [VAS] scale). Injection of diclofenac sodium $1.5 \mathrm{mg} / \mathrm{kg}$ IV in $100 \mathrm{ml}$ normal saline used as a relief analgesic for more than 20 minutes, and after that, once the VAS level is $\geq 4$.

Patients reported during the study for some adverse effects such as bradycardia, tachycardia (Pulserate $<$ or $>20$ percent of preoperative level in two consecutive readings), Hypotension and hypertension (mean arterial blood pressure $<$ or more than 20 percent of the preoperative level in two consecutive readings), postoperative sedation $>$ RSS 4 , respiratory depression (SPO 2 less than 90 percent) and respiratory depression (SPO $2<90$ percent).

\section{Statistical Methods:}

Data reported as $\mathrm{n}$ (present of cases) on categorical variables (such as age group, sex); Information on continuous variables (such as HR, BP, etc.) was described in two intervention groups as the Mean \pm Standard Deviation (SD). The statistical significance of categorical variables discrepancy between two intervention groups evaluated using the Chi-Square or Fisher 's exact probability test. The statistical value of the intergroup discrepancy in the mean of continuous variables measured using independent sample ' $t$ ' (unpaired Student's 't' test) test, after verifying the underlying assumption of normality. Pvalues of 0.05 shall be considered statistically significant. The data was statistically analysed using Statistical Package for Social Sciences (SPSS ver 16.0) for Microsoft Windows.

\section{Results}

The age, gender, ASA and BMI distribution did not differ significantly between the two intervention groups (Pvalue $>0.05$ ).
The average heart rate at $\mathrm{T} 0$ did not differ significantly between the twointervention groups ( $\mathrm{P}$-value $>0.05$ ). The average heart rate at time points (T1 to T11) is significantly higher in Group N compared to Group D (P-value $<0.05$ for all).

- The average systolic BP at T0, T1, T4, T8, T9, and T10 did not differ significantly between two intervention groups (Pvalue $>0.05$ for all).

- The average systolic BP at T2, T3, T5, T6, T7, and T11 is significantly higher in group $\mathrm{N}$ compared to group $\mathrm{D}$ (Pvalue $<0.05$ for all).

Two intervention groups (P-value $>0.05$ for both) did not vary significantly from the normal

Diastolic BP at $\mathrm{T} 0$ and $\mathrm{T} 4$. In group $\mathrm{N}$, the average diastolic $\mathrm{BP}$ at $\mathrm{T} 1, \mathrm{~T} 2, \mathrm{~T} 3, \mathrm{~T} 5, \mathrm{~T} 6, \mathrm{~T} 7$,

$\mathrm{T} 8, \mathrm{~T} 9, \mathrm{~T} 10$, and $\mathrm{T} 11$ is significantly higher than in group $\mathrm{D}$ (for both, the $\mathrm{P}$-value $<0.05$ ).

The mean peak arterial pressure at $\mathrm{T} 0, \mathrm{~T} 4$, and $\mathrm{T} 9$ was not significantly different between the two intervention groups (for both, P-value $>0.05$ ). The mean blood pressure at T1, T2, T3,

$\mathrm{T} 5, \mathrm{~T} 6, \mathrm{~T} 7, \mathrm{~T} 8, \mathrm{~T} 10$, and $\mathrm{T} 11$ in group $\mathrm{B}$ is significantly higher than in group $\mathrm{D}$ (for both, $\mathrm{P}$-value $<0.05$ ).

- The average SpO2 at all-time points (T0 to T11) did not differ significantlybetween two intervention groups (P-value $>0.05$ for all).

The average sedation score at $5 \mathrm{~min}, 15 \mathrm{~min}, 30 \mathrm{~min}$, and 60 min post extubation is significantly higher in group D compared to group N. (P-value $<0.001$ for all). The average pain score (VAS) after 5 min of extubation is significantly higher in group $\mathrm{N}$ compared to group $\mathrm{D}(\mathrm{P}$-value $<0.001$ ). The average time to rescue analgesia is significantly higher in group D compared to group B (P-value $<0.001)$.

\section{Discussion}

The study was conducted in 60 ASA grade I and II patients between the agegroup 18-65 years, posted for elective laparoscopic surgery. Patient's randomlyallocated either to receive a Normal saline infusion (group N) ordexmedetomidine infusion (group D). Each group had 30 patients. Both groupswere comparable, and there was no statistically significant difference withregards to mean age, BMI, gender distribution, and ASA grading. Dexmedetomidine infusion started at a rate of $0.4 \mathrm{mcg} / \mathrm{kg} / \mathrm{hr}$ in group D and normal saline as a placebo in group $\mathrm{N}$ from $10 \mathrm{~min}$ before induction until therelease of pneumoperitoneum in patients undergoing elective laparoscopic surgery. Parameters like HR, SBP, DBP, and MAP recorded at specific intervals.Patients were also observed for postoperative sedation and analgesiarequirement. In our study, after 10 


\begin{tabular}{|c|c|c|c|c|c|}
\hline \multirow{2}{*}{$\begin{array}{ll}\begin{array}{l}\text { Age } \\
\text { (years) }\end{array} & \text { Group } \\
\end{array}$} & \multicolumn{2}{|c|}{ Group D [Dexmed] $(\mathrm{n}=30)$} & \multicolumn{2}{|c|}{ Group N [Control] $(\mathrm{n}=\mathbf{3 0})$} & \multirow{2}{*}{$\begin{array}{l}\text { P-value (Group D vs } \\
\text { Group N) }\end{array}$} \\
\hline & $\mathbf{N}$ & $\%$ & $\mathbf{N}$ & $\%$ & \\
\hline $18.0-27.0$ & 5 & 16.7 & 9 & 30.0 & $0.566^{N S}$ \\
\hline $28.0-37.0$ & 10 & 33.3 & 5 & 16.7 & \\
\hline $38.0-47.0$ & 7 & 23.3 & 7 & 23.3 & \\
\hline $48.0-57.0$ & 5 & 16.7 & 5 & 16.7 & \\
\hline$>58.0$ & 3 & 10.0 & 4 & 13.3 & \\
\hline Total & 30 & 100.0 & 30 & 100.0 & \\
\hline \multicolumn{6}{|c|}{ Gender distribution } \\
\hline Male & 13 & 43.3 & 14 & 46.7 & $0.795 \mathrm{NS}$ \\
\hline Female & 17 & 56.7 & 16 & 53.3 & \\
\hline \multicolumn{6}{|l|}{ ASA distribution } \\
\hline Grade I & 23 & 76.7 & 21 & 70.0 & $0.559^{N S}$ \\
\hline Grade II & 7 & 23.3 & 9 & 30.0 & \\
\hline BMI $\left(\mathrm{kg} / \mathrm{m}^{2}\right)$ & 21.98 & 2.38 & 21.80 & 2.23 & $0.759^{N S}$ \\
\hline
\end{tabular}

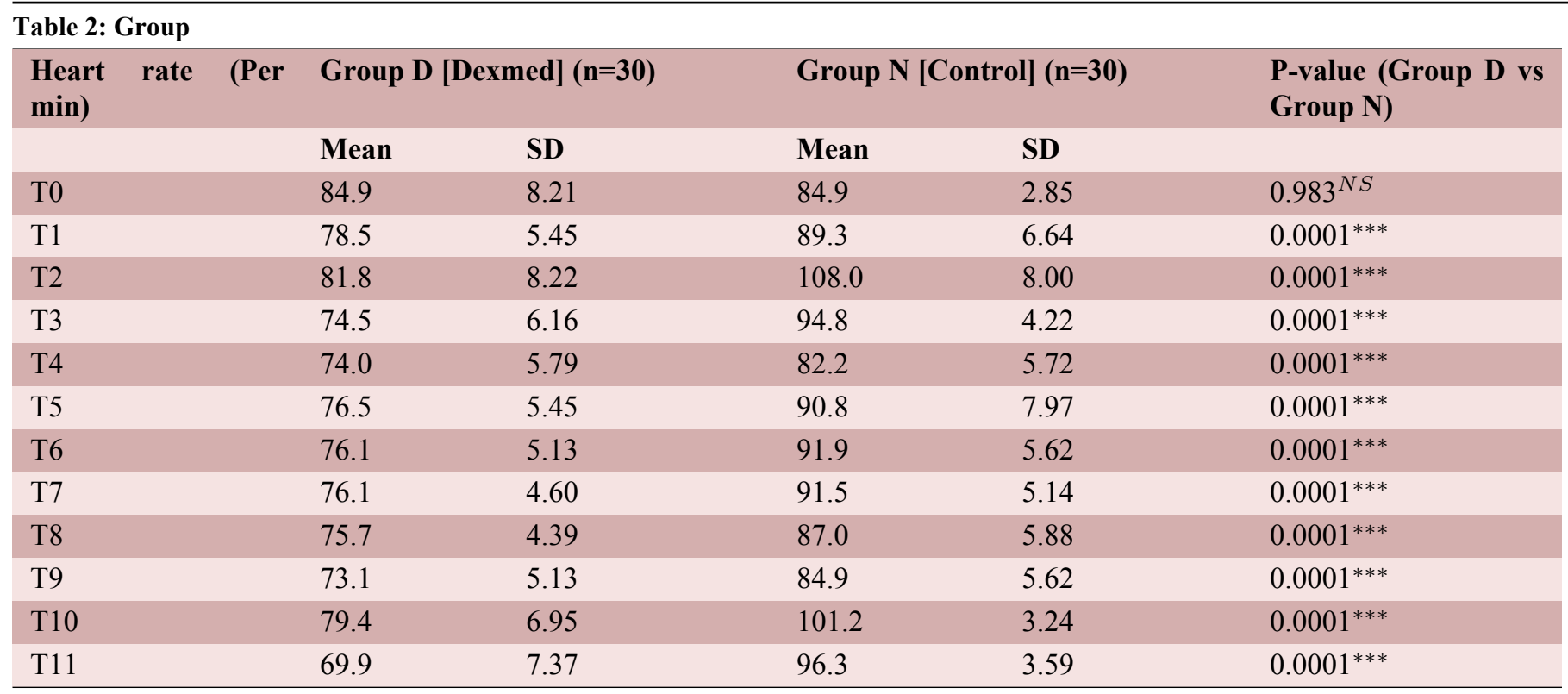

min infusion of dexmedetomidine and normal saline in group $\mathrm{D}$ and group $\mathrm{N}$ respectively, there was a fall in HR by $7.5 \%$ in group D. Fall in HR in group D was statistically significant compared to group N. which is in correlaton with Yildiz et al. (2006), ${ }^{[6]}$ observed that increase in heart rate after intubation was significantly low in the dexmedetomidine group compared to the placebo group. Dexmedetomidine group had received a single pre-induction intravenous dose of dexmedetomidine $1 \mathrm{mcg} / \mathrm{kg}$. Our results are consistent with this study.
Gogus N et al. (2014), ${ }^{[7]}$ studied the effects of dexmedetomidine, fentanyl, and esmolol on hemodynamic response to intubation. Group I received one $\mathrm{mcg} / \mathrm{kg}$ dexmedetomidine as an infusion over $10 \mathrm{~min}$, Group II received two $\mathrm{mcg} / \mathrm{kg}$ fentanyl, Group III received $2 \mathrm{mg} / \mathrm{kg}$ esmolol $2 \mathrm{~min}$ before induction. They found that dexmedetomidine was superior in the prevention of tachycardia following intubation. Our results are consistent with this study. In our study, after 10 min infusion of dexmedetomidine in group $\mathrm{D}$ and normal saline in group $\mathrm{N}$, there was a fall in SBP, DBP, and MAP by $8.8 \%, 16.8 \%$, and $13.6 \%$ respectively in group $\mathrm{D}$ which was statistically signifi- 


\begin{tabular}{|c|c|c|c|c|c|c|}
\hline \multirow{2}{*}{$\begin{array}{l}\text { Systolic } \\
\text { (mmHg) }\end{array}$} & \multirow[t]{2}{*}{ BP } & \multicolumn{2}{|c|}{ Group D [Dexmed] $(\mathrm{n}=30)$} & \multicolumn{2}{|c|}{ Group N [Control] $(\mathrm{n}=\mathbf{3 0})$} & \multirow{2}{*}{$\begin{array}{l}\text { P-value (Group D vs } \\
\text { Group N) }\end{array}$} \\
\hline & & Mean & SD & Mean & SD & \\
\hline T0 & & 135.9 & 7.53 & 132.9 & 9.42 & $0.164^{N S}$ \\
\hline $\mathrm{T} 1$ & & 123.9 & 7.53 & 128.3 & 15.26 & $0.172^{N S}$ \\
\hline $\mathrm{T} 2$ & & 131.0 & 6.71 & 146.6 & 9.49 & $0.001^{* * *}$ \\
\hline $\mathrm{T} 3$ & & 121.0 & 6.71 & 131.1 & 13.9 & $0.001^{* * *}$ \\
\hline $\mathrm{T} 4$ & & 122.2 & 4.76 & 118.8 & 11.9 & $0.152^{N S}$ \\
\hline T5 & & 127.4 & 4.34 & 137.9 & 15.71 & $0.001^{* * *}$ \\
\hline T6 & & 128.3 & 4.15 & 138.3 & 15.04 & $0.001^{* * *}$ \\
\hline $\mathrm{T} 7$ & & 130.4 & 4.25 & 141.0 & 15.05 & $0.001^{* * *}$ \\
\hline $\mathrm{T} 8$ & & 128.4 & 4.25 & 130.7 & 14.09 & $0.382^{N S}$ \\
\hline T9 & & 120.4 & 4.25 & 121.0 & 15.93 & $0.834^{N S}$ \\
\hline $\mathrm{T} 10$ & & 133.0 & 6.71 & 137.4 & 11.20 & $0.070^{N S}$ \\
\hline T11 & & 120.3 & 4.76 & 127.8 & 9.16 & $0.001^{* * *}$ \\
\hline
\end{tabular}

Table 4: The inter-group comparison of Diastolic BP at each time interval $(n=60)$.

\begin{tabular}{|c|c|c|c|c|c|}
\hline \multirow{2}{*}{$\begin{array}{l}\text { Diastolic } \mathrm{BP} \\
(\mathrm{mmHg})\end{array}$} & \multicolumn{2}{|c|}{ Group D [Dexmed] $(\mathrm{n}=30)$} & \multicolumn{2}{|c|}{ Group N [Control] $(\mathrm{n}=\mathbf{3 0})$} & \multirow{2}{*}{$\begin{array}{l}\text { P-value (Group D vs } \\
\text { Group N) }\end{array}$} \\
\hline & Mean & SD & Mean & SD & \\
\hline T0 & 85.9 & 4.81 & 82.7 & 8.21 & $0.073^{N S}$ \\
\hline $\mathrm{T} 1$ & 71.4 & 6.89 & 78.5 & 8.14 & $0.001^{* * *}$ \\
\hline $\mathrm{T} 2$ & 71.9 & 6.49 & 94.4 & 6.69 & $0.001^{* * *}$ \\
\hline $\mathrm{T} 3$ & 64.6 & 4.79 & 88.9 & 13.00 & $0.001^{* * *}$ \\
\hline $\mathrm{T} 4$ & 72.3 & 4.20 & 78.1 & 15.85 & $0.059^{N S}$ \\
\hline T5 & 75.4 & 4.56 & 86.1 & 11.20 & $0.001^{* * *}$ \\
\hline T6 & 74.8 & 4.11 & 82.7 & 10.55 & $0.001^{* * *}$ \\
\hline $\mathrm{T} 7$ & 73.7 & 4.10 & 80.8 & 11.55 & $0.003^{* *}$ \\
\hline T8 & 69.4 & 6.11 & 78.4 & 13.78 & $0.002^{* *}$ \\
\hline T9 & 67.2 & 8.62 & 73.9 & 15.04 & $0.038^{*}$ \\
\hline $\mathrm{T} 10$ & 83.9 & 4.81 & 88.7 & 7.58 & $0.005^{* *}$ \\
\hline $\mathrm{T} 11$ & 71.2 & 4.07 & 75.2 & 8.29 & $0.022^{*}$ \\
\hline
\end{tabular}

cant compared togroup $\mathrm{N}$.

In our study average systolic BP at T2, T3, T5, T6, T7, and $\mathrm{T} 11$ is stastically significantly higher ingroup $\mathrm{N}$ compared to group D and in group N, the average diastolic BP at T1,

T2, T3, T5, T6, T7, T8, T9, T10, and T11 is significantly higher than in group D. which correlates with Kallio et al. (1989), ${ }^{[8]}$ a dose-dependent decrease in systolic and diastolic blood pressure following administration of dexmedetomidine in singleintravenous doses of $12.5,25,50$, and $75 \mathrm{mcg}$ over 30 seconds to *ve healthy male volunteers as part of a placebocontrolled study. Our results are consistent with this study.
Patel Chirag et al. (2012), ${ }^{[9]}$ observed a significant fall in SBP and DBP of $6 \%$ and $9 \%$ respectively from baseline in patients $10 \mathrm{~min}$ after administration of $1 \mathrm{mcg} / \mathrm{kg}$ of dexmedetomidine over $10 \mathrm{~min}$ as compared to control group.Our results are consistent with this study. Sukhminder Jit Singh Bajwa et al (2012), ${ }^{[10]}$ also observed a transient increasein HR and MAP initially for 3-5 min after starting dexmedetomidine infusion of $1 \mathrm{mcg} / \mathrm{kg}$ over $20 \mathrm{~min}$. Biphasic responses found in this study might be due tothe use of a higher dose of dexmedetomidine..

We did not observe a biphasic response in our study. This response might bedue to the lower dose of dexmedetomidine used in our study, $0.4 \mathrm{mcg} / \mathrm{kg} / \mathrm{hr}$, that too, given in the form of 


\begin{tabular}{|c|c|c|c|c|c|}
\hline \multirow[t]{2}{*}{ SPO2 (\%) } & \multicolumn{2}{|c|}{ Group D [Dexmed] $(\mathrm{n}=30)$} & \multicolumn{2}{|c|}{ Group N [Control] $(n=30)$} & \multirow{2}{*}{$\begin{array}{l}\text { P-value (Group D vs } \\
\text { Group N) }\end{array}$} \\
\hline & Mean & SD & Mean & SD & \\
\hline T0 & 100.0 & 0.00 & 99.9 & 0.35 & $0.999^{N S}$ \\
\hline $\mathrm{T} 1$ & 99.7 & 0.48 & 100.0 & 0.00 & $0.999^{N S}$ \\
\hline $\mathrm{T} 2$ & 100.0 & 0.00 & 100.0 & 0.00 & $0.999^{N S}$ \\
\hline $\mathrm{T} 3$ & 100.0 & 0.00 & 100.0 & 0.00 & $0.999^{N S}$ \\
\hline $\mathrm{T} 4$ & 100.0 & 0.00 & 100.0 & 0.00 & $0.999^{N S}$ \\
\hline T5 & 100.0 & 0.00 & 100.0 & 0.00 & $0.999^{N S}$ \\
\hline T6 & 100.0 & 0.00 & 100.0 & 0.00 & $0.999^{N S}$ \\
\hline $\mathrm{T} 7$ & 100.0 & 0.00 & 100.0 & 0.00 & $0.999^{N S}$ \\
\hline $\mathrm{T} 8$ & 100.0 & 0.00 & 100.0 & 0.00 & $0.999^{N S}$ \\
\hline T9 & 100.0 & 0.00 & 100.0 & 0.00 & $0.999^{N S}$ \\
\hline $\mathrm{T} 10$ & 100.0 & 0.00 & 100.0 & 0.00 & $0.999^{N S}$ \\
\hline $\mathrm{T} 11$ & 99.6 & 0.49 & 99.8 & 0.43 & $0.999^{N S}$ \\
\hline
\end{tabular}

Table 6: The inter-group comparison of postoperative sedation, pain score and rescue analgesia at each time interval (n=60).

\begin{tabular}{|llllll|}
\hline $\begin{array}{l}\text { Sedation Score after extu- } \\
\text { bation }\end{array}$ & \multicolumn{2}{l}{ Group D [Dexmed] $\mathbf{( n = 3 0 )}$} & Group N [Control] $(\mathbf{n}=\mathbf{3 0})$ & $\begin{array}{l}\text { P-value (Group D vs } \\
\text { Group N) }\end{array}$ \\
\hline & Mean & SD & Mean & SD & \\
\hline 5 - Min & 2.43 & 0.50 & 1.57 & 0.73 & $0.001^{* * *}$ \\
\hline 15 - Min & 2.20 & 0.48 & 1.43 & 0.50 & $0.001^{* * *}$ \\
\hline 30- Min & 2.10 & 0.30 & 1.40 & 0.49 & $0.001^{* * *}$ \\
\hline $60-$ Min & 1.80 & 0.41 & 1.33 & 0.48 & $0.001^{* * *}$ \\
\hline Pain Score & 0.77 & 0.67 & 2.13 & 0.68 & $0.001^{* * *}$ \\
\hline Time to rescue analgesia & 80.8 & 15.98 & 33.8 & 7.73 & $0.001^{* * *}$ \\
\hline
\end{tabular}

infusion. R. Saraf et al (2013), ${ }^{[11]}$ also did not observe biphasic response with a dexmedetomidine dose of $0.6 \mathrm{mcg} / \mathrm{kg}$ diluted to $10 \mathrm{ml} \mathrm{NS}$ given over $10 \mathrm{~min}$ before induction. This response might be due to the use of a lower dose of dexmedetomidine in their study. Our results are consistent with this study. Our study showed a maximal average increase of $5.7 \%$ and $14.26 \%$ in SBP and $0.7 \%$ and $20.25 \%$ in DBP in group D and group $\mathrm{N}$, respectively, during laryngoscopy and tracheal intubation. This increase was significantly higher in group $\mathrm{N}$ compared to group D. Difference found in both the groups was statistically significant. Thus attenuation in SBP and DBP was seen in group $\mathrm{D}$ as compared to group $\mathrm{N}$ during laryngoscopy and tracheal intubation, which was statistically significant.

Yildiz $\mathrm{M}$ et al (2006), ${ }^{[6]}$ observed that an increase in blood pressure afterintubation was significantly low in the dexmedetomidine group $(\mathrm{p}<0.05)$ compared to the placebo group. Dexmedetomidine group had received a single preinduction intravenous dose of dexmedetomidine $1 \mathrm{mcg} / \mathrm{kg}$. Our results are consistent with this study.Our study showed that an increase in HR, SBP, DBP, and MAP at $2 \mathrm{~min}, 5 \mathrm{~min}$, and 10 min after the creation of pneumoperitoneum was significantly higher ingroup $\mathrm{N}$ compared to group D. Difference found in both the groups wasstatistically significant. Thus attenuation in HR, SBP, DBP, and MAP at $2 \mathrm{~min}, 5 \mathrm{~min}$, and $10 \mathrm{~min}$ after the creation of pneumoperitoneum was seen in group $\mathrm{D}$ as compared to group $\mathrm{N}$, which was statistically significant. In the study done by Shah Vandana et al (2015), ${ }^{[12]}$ In the study done by Shah Vandana et al $(2015) 31$, Group D $(n=25)$ received dexmedetomidine $1 \mathrm{mcg} / \mathrm{kg} / \mathrm{min}$ loading dose followed by $0.2-$ $0.7 \mathrm{mcg} / \mathrm{kg} / \mathrm{hr}$ infusion titrated to maintain BIS value between $40-60$ and vitals. Group P $(n=25)$ received $25-75 \mathrm{mcg} / \mathrm{kg} / \mathrm{min}$

Propofol infusion titrated to maintain BIS value between 40-60 and vitals. Theyfound that dexmedetomidine causes attenuation of hemodynamic response tolaryngoscopy and pneumoperitoneum. Also, maintain the depth of anesthesia better than propofol. Our results are consistent with this study. 
Group E received a bolus injection of $500 \mathrm{mcg} / \mathrm{kg}$ intravenous esmolol before pneumoperitoneum followed by an infusion of $100 \mathrm{mcg} / \mathrm{kg} / \mathrm{min}$ in the study conducted by Dhurjoti Prosad Bhattacharjee et al. (2016), ${ }^{[13]}$ Group D obtained $1 \mathrm{mcg} / \mathrm{kg}$ IV dexmedetomidine before pneumoperitoneum with a bolus injection accompanied by $0.2 \mathrm{mcg} / \mathrm{kg} / \mathrm{h}$ infusion. Group $\mathrm{S}$ (control) provided 0.9 per cent saline. Our findings are in accordance with the study Group 1 received $2 \mathrm{mcg} / \mathrm{kg}$ of clonidine diluted in normal saline in the study performed by S Kumar et al. (2014), providing gradual intravenous infusion over 10 min until general anesthesia was induced. Group 2 obtained $1 \mathrm{mcg} / \mathrm{kg}$ of dexmedetomidine diluted in regular saline, given slow intravenous infusion more than 10 minutes before general anesthetic induction. They also found that dexmedetomidine and clonidine are effective in attenuating the pneumoperitoneum hemodynamic response with equal efficacy and without significant side effects in patients. Our conclusions are consistent with the report.

Recep Aksu et al (2009), ${ }^{[14]}$ used dexmedetomidine $0.5 \mathrm{mcg} / \mathrm{kg}$ and fentanyl $1 \mathrm{mcg} / \mathrm{kg}, 5 \mathrm{~min}$ before extubation. They found that dexmedetomidine is more effective than fentanyl in attenuating hemodynamic response to extubation. Our results are partially inconsistent with this study as attenuation in SBP was not statistically significant in group D compared to group $\mathrm{N}$. which might be so because we stopped dexmedetomidine infusion at the time of the release of pneumoperitoneum, while in the above study, dexmedetomidine was given 5 min before extubation. In our study, the average sedation score at $5 \mathrm{~min}, 15 \mathrm{~min}, 30 \mathrm{~min}$, and $60 \mathrm{~min}$ postextubation was significantly higher in group D compared to group N. Difference found in both the groups was statistically significant. Postextubation, patients were more comfortable in group $\mathrm{D}$ compared to group $\mathrm{N}$.

In our study average sedation score at $5 \mathrm{~min}, 15 \mathrm{~min}, 30$ min, and 60 min post extubation is significantly higher in group D compared to group $\mathrm{N}$. The average pain score (VAS) after $5 \mathrm{~min}$ of extubation is significantly higher in group N compared to group D. Yildiz et al (2006) found that patients in the dexmedetomidine group had sedation levels of 3 and 4 at $10 \mathrm{~min}$. Our findings are consistent with this analysis as in most patients in group D at 5 and 15 min after extubation in our study a sedation level was 2 and 3. Our result The average time to rescue analgesia is significantly higher in group D compared to group B showing the benefits of the analgesic effect of dexmedetomidine is consistent with Varshali Keniya et al (2011) ${ }^{[15]}$ observed that intraoperative fentanyl requirement was $100 \pm 10 \mathrm{mcg}$ in the control group and $60 \pm 10 \mathrm{mcg}$ in thedexmedetomidine group. Control group had received isofurane-opioid and study group had received isofurane-opioid-dexmedetomidine $(1 \mathrm{mcg} / \mathrm{kg}$ dexmedetomidine was given over $10 \mathrm{~min}$ before the induction of anesthesia and was continued in a dose of $0.2-0.7 \mathrm{mcg} / \mathrm{kg} / \mathrm{hr}$ to keep the hemodynamic parameters within acceptable range till the start of skin closure) in their study. S Kumar et al (2014), ${ }^{[16]}$ also found that the mean sedation level of the dexmedetomidine group at the time of extubation $(2.93 \pm$ 0.50 ) was significantly higher than that of the clonidine group $(1.60 \pm 0.50)$, and patients were more comfortable during the postoperative period. Our result is consistent with the analysis.

\section{Conclusion}

Laparoscopic surgery is associated with haemodynamic stress response to intuabation, pneumoperitoneum and extubation. These insults can be disastrous in high risk patients especially those with cardiopulmonary diseases. Hence, it is of utmost importance to maintain haemodynamic stability in these patients.

In our analysis, we concluded that $0.4 \mathrm{mcg} / \mathrm{kg} / \mathrm{hr}$ infusion of dexmedetomidine started 10 minutes before activation of pneumoperitoneum anaesthesia without any dose of bolus; it serves as a very useful anesthesia adjuvant to attenuate the response of haemodynamic stress to patients with intubation, pneumoperitoneum, and extubation patients undergoing laparoscopic surgery. This also increases postoperative sedation and reduces postoperative analgesic needs, without significant side effects.

\section{References}

1. Jean L, Ronald D, Miller LI, Eriksson LA, Fleisher JP, Wienener-Kronish WL, et al. Miller's Anaesthesia. 2010;68:2185-2202.

2. Khan ZP, Munday IT, Jones RM, Thornton C, Mant TG, Amin D. Effects of dexmedetomidine on isoflurane requirements in healthy volunteers. 1: Pharmacodynamic and pharmacokinetic interactions. Br J Anaesth. 1999;83(3):372-380. Available from: https://doi.org/10.1093/bja/83.3.372.

3. Ramsay MAE, Saha D, Hebeler RF. Tracheal resection in the morbidly obese patient: the role of dexmedetomidine. J Clin Anesth. 2006;18(6):452-454. Available from: https://doi.org/ 10.1016/j.jclinane.2006.02.004.

4. Tufanogullari B, White PF, Peixoto MP, Kianpour D, Lacour $\mathrm{T}$, Griffin J, et al. Dexmedetomidine Infusion During Laparoscopic Bariatric Surgery: The Effect on Recovery Outcome Variables. Anesth Analg. 2008;106(6):1741-1748. Available from: https://doi.org/10.1213/ane.0b013e318172c47c.

5. Bloor BC, Ward DS, Belleville JP, Maze M. Effects of intravenous dexmedetomidine in humans. II. Hemodynamic changes. Anesthesiology. 1992;77(6):1134-1142. Available from: https://doi.org/10.1097/00000542-199212000-00014.

6. Yildiz M, Tavlan A, Tuncer S, Reisli R, Yosunkaya A, Otelcioglu S. Effect of dexmedetomidine on haemodynamic responses to laryngoscopy and intubation : perioperative haemodynamics and anaesthetic requirements. Drugs R D. 2006;7(1):43-52. Available from: https://doi.org/10.2165/ 00126839-200607010-00004. 
7. Gogus N, Akan B, Serger N, Baydar M. The comparison of the effects of dexmedetomidine, fentanyl and esmolol on prevention of hemodynamic response to intubation. Rev Bras Anestesiol. 2014;64(5):314-319. Available from: https://dx. doi.org/10.1016/j.bjane.2013.10.012.

8. Kallio A, Scheinin M, Koulu M, Ponkilainen R, Ruskoaho H, Viinamäki O, et al. Effects of dexmedetomidine, a selective $\alpha 2$ adrenoceptor agonist, on hemodynamic control mechanisms. Clin Pharmacol Ther. 1989;46(1):33-42. Available from: https: //dx.doi.org/10.1038/clpt.1989.103.

9. Patel C, Engineer S, Shah B, Madhu S. Effect of intravenous infusion of dexmedetomidine on perioperative haemodynamic changes and postoperative recovery: A study with entropy analysis. Indian J Anaesth. 2012;56(6):542-542. Available from: https://doi.org/10.4103/0019-5049.104571.

10. Bajwa SJ, Singh A, Singh G, Gupta S, Panda A, Kaur J, et al. Attenuation of pressor response and dose sparing of opioids and anaesthetics with pre-operative dexmedetomidine. Indian J Anaesth. 2012;56(2):123-123. Available from: https://dx.doi. org/10.4103/0019-5049.96303.

11. Saraf R, Jha M, V SK, Damani K, Bokil S, Galante D. Dexmedetomidine, the ideal drug for attenuating the pressor Response. Pediatric Anesthesia and. Crit Care J. 2013;1(1):7886.

12. Vandana S, Janak P, Kirti P. Comparison of Dexmedetomidine and Propofol for hemodynamic changes and depth of anaesthesia (using BIS monitor) during laparoscopic surgery. NHL J Med Sci. 2015;4(1):44-48.

13. Bhattacharjee DP, Saha S, Paul S, Roychowdhary S, Mondal S, Paul S. A comparative study of esmolol and dexmedetomidine on hemodynamic responses to carbon dioxide pneumoperitoneum during laparoscopic surgery. Anesth Essays Res. 2016;10(3):580-584. Available from: https://dx.doi.org/ 10.4103/0259-1162.183564.
14. Aksu R, Akin A, Biçer C, Esmaoğlu A, Tosun Z, Boyaci A. Comparison of the effects of dexmedetomidine versus fentanyl on airway reflexes and hemodynamic responses to tracheal extubation during rhinoplasty: A double-blind, randomized, controlled study. Curr Ther Res Clin Exp. 2009;70(3):209220. Available from: https://doi.org/10.1016/j.curtheres.2009. 06.003 .

15. Keniya V, Naphade R, Ladi S. Dexmedetomidine attenuates sympathoadrenal response to tracheal intubation and reduces perioperative anaesthetic requirement. Indian J Anaesth. 2011;55(4):352-352. Available from: https://dx.doi.org/10. 4103/0019-5049.84846.

16. Kumar S, Kushwaha BB, Prakash R, Jafa S, Malik A, Wahal R, et al. Comparative Study of Effects of Dexmedetomidine and Clonidine Premedication in Perioperative Hemodynamic Stability And Postoperative Analgesia In Laparoscopic Cholecystectomy. Internet J Anesthesiol. 2014;33(1):1-8.

Copyright: (C) the author(s), 2020. It is an open-access article distributed under the terms of the Creative Commons Attribution License (CC BY 4.0), which permits authors to retain ownership of the copyright for their content, and allow anyone to download, reuse, reprint, modify, distribute and/or copy the content as long as the original authors and source are cited.

How to cite this article: Sankar VR, Jamuna T, Raju B. Compare the Effects of Dexmedetomidine Infusion versus Normal Saline as Placebo on Haemodynamic Response in Elective Laparoscopic Surgery Under General Anaesthesia. Acad. Anesthesiol. Int. 2020;5(2):1-8.

DOI: dx.doi.org/10.21276/aan.2020.5.2.1

Source of Support: Nil, Conflict of Interest: None declared. 